\title{
ANALISIS PENGARUH BAHASA GAUL DI KALANGAN MAHASISWATERHADAP BAHASA INDONESIA DI ZAMAN SEKARANG
}

\author{
Muhammad Ridlo, Yuman Satriyadi, Nadhira Azzahra, Anandita Husnaini Nasution \\ Program Studi Teknik Elektro, Institut Teknologi Bandung \\ Email: muhridlo2407@gmail.com
}

\begin{abstract}
Abstrak
Perkembangan arus teknologi dan media yang semakin pesat, telah berdampak pada berbagai sektor di masyarakat, salah satunya penggunaan bahasa yang baik dan benar. Di masa sekarang, khususnya di kalangan mahasiswa munculnya tren baru yaitu bahasa gaul. Bahasa gaul adalah bahasa yang biasanya digunakan remaja dengan menggunakan istilah-istilah keren dalam berbicara sehari-hari. beberapa contoh kosakata bahasa gaul yaitu "mantul", "santuy", dan lain sebagainya. Penggunaan bahasa menimbulkan polemik di masyarakat terhadap perkembangan bahasa indonesia di kalangan mahasiswa. Tujuan dalam penelitian ini adalah untuk mengetahui pengaruh bahasa gaul terhadap bahasa indonesia, untuk mengetahui kosakata bahasa gaul, perkembangan bahasa gaul dikalangan mahasiswa, serta dampak positif dan negatif dari bahasa gaul. Metode yang digunakan dalam pengumpulan data menggunakan metode survei yang diberikan pada beberapa responden dan juga metode studi literatur yang didapatkan dari buku, majalah, dan internet terkait permasalahan yang sedang diteliti. Keterbaruan dalam penelitian ini adalah penggunaan bahasa gaul terhadap perkembangan bahasa indonesia di kalangan mahasiswa.
\end{abstract}

Kata Kunci : bahasa, gaul, Indonesia, mahasiswa, perkembangan

\begin{abstract}
The rapidness of technology and social media development has had an impact on various sectors in society, one of them is the good and correct usage of language. Nowadays, especially among college students, there is an emergence of a new trend that is slang. Slang is the language that teenagers usually use by using cool terms in everyday speech. A few examples of slang vocabulary are "mantul", "santuy", et cetera. The usage of language raises polemics in society regarding the level of politeness in speech. The purpose of this study was to determine the influence of slang on Bahasa Indonesia, to know the vocabulary of slang, the development of slang among college students, as well as the positive and negative impacts of slang. The method used in data collection uses a survey method given to several respondents and also literature study method obtained from books, magazines, and the internet related to the problem that is being studied. The novelty in this study is the use of slang on the development of Bahasa Indonesian among college students.
\end{abstract}

Keyword : language, slang, Indonesia, student, development

\section{PENDAHULUAN}

Dalam kehidupan sehari-hari manusia tidak pernah terlepas dari pemakaian bahasa. Dengan adanya bahasa, manusia dapat berkomunikasi antara satu dan lainya, menyampaikan ide, dan lainlain. Bahasa indonesia merupakan bahasa persatuan yang digunakan seluruh masyarakat indonesia dalam kehidupan sehari-hari (Rachman, Ryan, et al., 2021). Di zaman sekarang penggunaan bahasa indonesia mulai bergeser digantikan oleh pemakaian bahasa anak remaja yang dikenal dengan bahasa gaul. Interferensi bahasa gaul kadang muncul dalam penggunaan bahasa Indonesia dalam situasi resmi yang mengakibatkan penggunaan bahasa tidak baik dan tidak benar. Pengguna bahasa gaul ini kebanyakan berasal dari generasi $\mathrm{Z}$ (Rachman, Nurgiansah, et al., 2021).

Generasi $\mathrm{Z}$ merupakan generasi yang lahir sekitar tahun 1996-2010, yang berusia 11 - 25 tahun di tahun 2011. Mahasiswa berada dalam rentang usia generasi dan merupakan bagian dari generasi Z. Mayoritas mahasiswa sebagai yang merupakan bagian dari generasi $\mathrm{Z}$ 
kerap menggunakan bahasa gaul dalam berkomunikasi sehari-hari (Dewantara, Hermawan, et al., 2021).

Penelitian ini dilakukan dengan tujuan untuk mengetahui tingkat penggunaan kosakata serta percakapan menggunakan bahasa gaul, serta mengamati perkembangan bahasa gaul di kalangan mahasiswa. Hal ini didasari karena penulis menyadari adanya perubahan sikap secara individu, serta perubahan budaya antardaerah dari waktu ke waktu. Penelitian ini diharapkan dapat bermanfaat baik bagi penulis maupun pembaca. Bagi para pembaca, penelitian ini diharapkan dapat memberi manfaat sebagai wawasan umum untuk mengetahui penggunaan bahasa Indonesia di kalangan masyarakat. Selain itu, penggunaan bahasa di Indonesia sangatlah beragam dan saling berkolaborasi, terutama di kalangan mahasiswa. Mahasiswa dari seluruh daerah di Indonesia menggunakan bahasa yang berbeda-beda, sehingga diperlukan penyesuaian bahasa bagi mahasiswa yang pergi ke luar daerah asalnya. Selain itu, penelitian ini dapat bermanfaat sebagai sarana kajian terkait analisis penyebaran dan pengaruh bahasa gaul di seluruh Indonesia. Bagi penulis, penelitian ini dapat menjadi wadah sebagai bahan pelajaran dan pengajaran serta sebagai wadah introspeksi diri dalam memahami bahasa Indonesia sebagai bahasa negara Indonesia.

\section{METODE PENELITIAN}

Metode penelitian yang digunakan dalam penelitian ini ada dua metode yaitu kualitatif dan kuantitatif. Metode kualitatif dengan jenis penelitian yaitu Studi Deskriptif literatur dimana Teknik pengumpulan data berupa aspek kebahasaan, yaitu frasa, klausa, dan kalimat dari bahasa gaul. Hal ini terkait pengaruh penggunaan bahasa gaul terhadap bahasa indonesia di kalangan mahasiswa. Sedangkan metode penelitian kuantitatif berupa survei yang dilaksanakan dengan menggunakan form secara daring digunakan untuk melihat persebaran dari responden dan kosakata bahasa gaul yang digunakan oleh responden. dimana teknik pengumpulan data dengan melihat respon dari mahasiswa melalui survey daring terkait variabel yang diteliti (kosakata bahasa gaul).

Survei dilakukan secara daring menggunakan form yang telah disediakan terkait aspek yang ingin dikaji untuk melihat korelasi antara penggunaan bahasa gaul dikalangan mahasiswa terhadap bahasa indonesia di zaman sekarang. dengan jumlah responden 96 orang yang tersebar di beberapa wilayah di indonesia yang sedang menempuh pendidikan S1 (mahasiswa) di beberapa perguruan tinggi. untuk mendapatkan data yang valid maka responden yang mengisi harus sesuai dengan kriteria penelitian.

Berikut ditampilkan persentase persebaran responden berdasarkan asal daerah dari responden sebagai berikut :

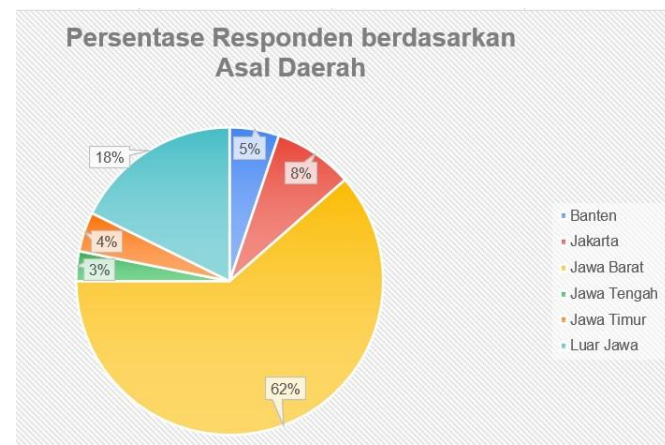

Gambar 1. Persentase Responden Berdasarkan
Asal Daerah.

Berikutnya, di bawah ini adalah persebaran responden berdasarkan universitas sebagai berikut : 


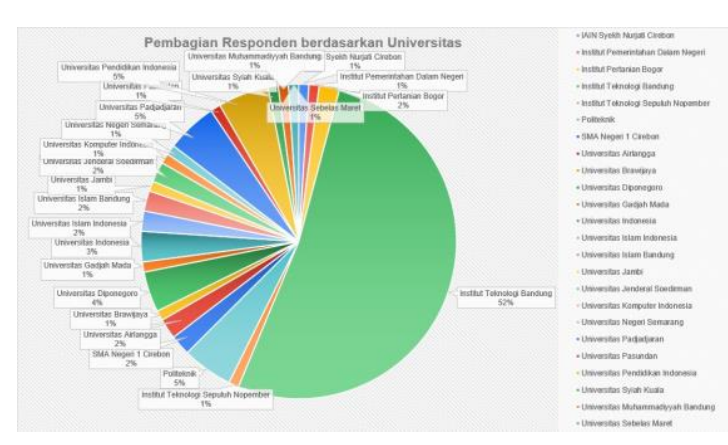

Gambar 2. Pembagian Responden Berdasarkan Universitas

Dari survei yang telah disebarkan, didapatkan 47 Laki-laki dan 49 Perempuan yang mengisi survei sesuai dengan bagan di bawah ini:

PERSENTASE RESPONDEN BERDASARKAN GENDER

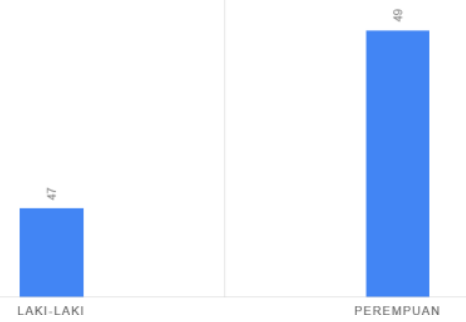

Gambar 3. Persentase Responden Berdasarkan Gender

Berikutnya, ditampilkan penyebaran usia responden survei yang ditampilkan dengan grafik batang, sebagai berikut.

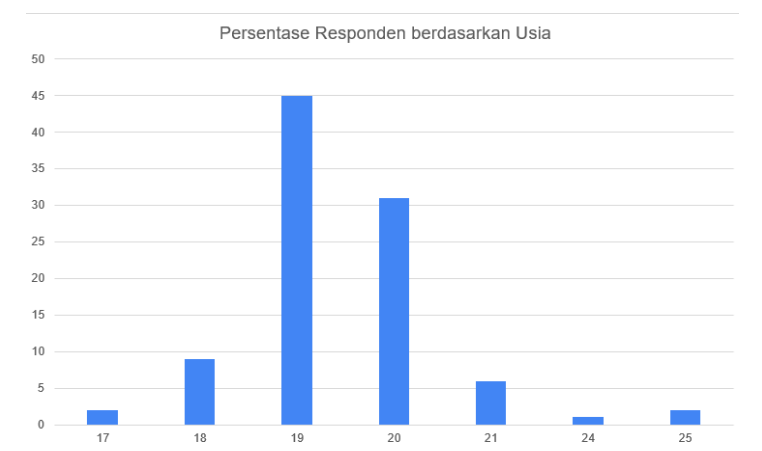

Gambar 4. Persentase Responden Berdasarkan Usia

HASIL PENELITIAN DAN PEMBAHASAN Hasil Penelitian Pengertian Bahasa
Dikutip dari Gorys Keraf dalam (Dewantara \& Nurgiansah, 2021a), bahasa merupakan alat atau media yang digunakan untuk berkomunikasi antarmanusia yang dihasilkan oleh alat pengucap manusia. Setiap komunitas memungkinkan memiliki bahasa yang berbeda-beda, dipengaruhi oleh faktorfaktor, seperti faktor geografis yang menimbulkan kebudayaan yang berbedabeda di setiap daerah (Dewantara, Nurgiansah, et al., 2021).

Secara umum, bahasa digunakan sebagai wadah untuk mengekspresikan emosi diri. Sebagai contoh, emosi sedih yang direalisasikan dengan ungkapan kesedihan. Selain itu, bahasa juga digunakan sebagai alat untuk berinteraksi kepada orang lain (Dewantara \& Nurgiansah, 2021c). Bayangkan apabila tidak ada bahasa di dunia ini, peradaban tidak akan bisa berkembang ke arah yang baik. Selain itu juga, bahasa digunakan sebagai persatuan antara komunitas dan lingkungan sosial yang berbeda.

Menurut Mulyono (2008) dan (Dewantara \& Nurgiansah, 2021b), bahasa gaul merupakan bahasa adaptasi dari bahasa baku, contohnya bahasa Indonesia, yang memiliki arti unik, khusus, yang berbeda dengan bahasa lazim yang dipakai manusia. Bahasa gaul sering digunakan oleh beberapa komunitas untuk melakukan percakapan di kehidupan sehari-hari. Secara umum, bahasa gaul yang berkembang di masyarakat dapat berubahubah sesuai zamannya. Saat ini, bahasa gaul dapat dengan mudah berkembang luas melalui teknologi seperti internet (Nurgiansah, 2020).

\section{Pengertian Generasi Z}

Generasi Z merupakan generasi kelahiran manusia yang terukur sejak tahun 1996 sampai 2012. Berdasarkan statusnya, generasi $\mathrm{Z}$ terhitung setelah generasi milenial, yang merupakan generasi yang muncul di tengah perkembangan teknologi, dengan contoh- 
nya yaitu keturunan dari generasi $\mathrm{X}$ dan Milenial (Rastati, 2018) (Nurgiansah, 2021a).

\section{Pembahasan}

\section{Pengaruh Penggunaan Bahasa Gaul terhadap Bahasa Indonesia}

Bahasa gaul banyak digunakan oleh berbagai kalangan masyarakat. Di kalangan remaja, khususnya mahasiswa, banyak dari mereka yang menyisipkan kata-kata gaul dalam melakukan percakapan dengan orang lain dalam kehidupan sehari-hari. Dari hasil survei yang dilakukan pada 96 mahasiswa dari berbagai daerah dan universitas, didapat penjelasan bahwa $33.24 \%$ dari total responden, atau sebanyak 32 responden, sangat sering menggunakan bahasa gaul dalam melakukan percakapan. Selain itu, dari survei yang dilakukan, sebanyak $47.87 \%$ atau sebanyak 46 responden, juga sering menggunakan bahasa gaul.

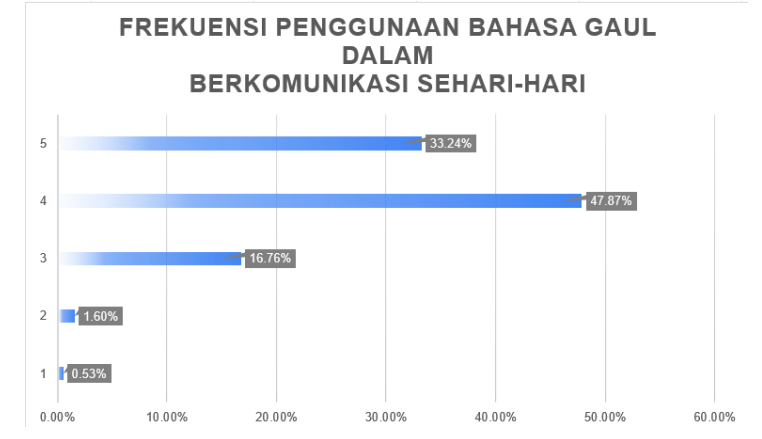

Gambar 5. Frekuensi Penggunaan Bahasa Gaul Dalam Berkomunikasi Sehari-Hari

Secara umum, penggunaan bahasa gaul dilakukan untuk mempermudah serta mempercepat komunikasi dari suatu kelompok (Nurgiansah, 2021b). Hal ini dapat memberikan dampak positif dan negatif tepatnya ketika bahasa gaul digunakan di waktu dan tempat yang semestinya. Di antara dampak negatif yang didapat apabila terlalu sering menggunakan bahasa gaul dalam melakukan percakapan adalah dapat memberikan potensi tersingkirnya penggunaan bahasa Indonesia yang baik dan benar. Hal ini dibuktikan dengan data yang didapat berdasarkan jawaban dari kuesioner yang diberikan. Pertanyaan yang diberikan adalah "abis kelas mau ngapain?". Dari data jawaban, diperoleh hasil bahwa mayoritas responden menjawab dengan sisipan kata "mau" sebagai kata penghubung, padahal kata tersebut tidak baku jika digunakan sebagai kata penghubung dalam sebuah kalimat.

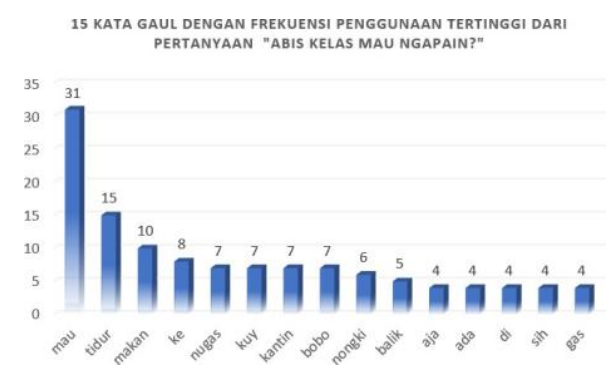

\section{Gambar 6. 15 Kata Gaul Frekuensi Tertinggi Dari Pertanyaan 1}

Selain pertanyaan tersebut, di kuesioner terdapat pertanyaan "Lu lagi ngapain sih?". Dari jawaban responden, didapat penjelasan bahwa kata dengan frekuensi tertinggi yang digunakan dalam menjawab pertanyaan ini adalah kata "lagi". Padahal, kata tersebut tidak baku apabila digunakan sebagai kata pengganti "sedang". Selain itu, berdasarkan data, kata "sedang" sangat jarang digunakan untuk menjawab pertanyaan kuesioner tersebut.

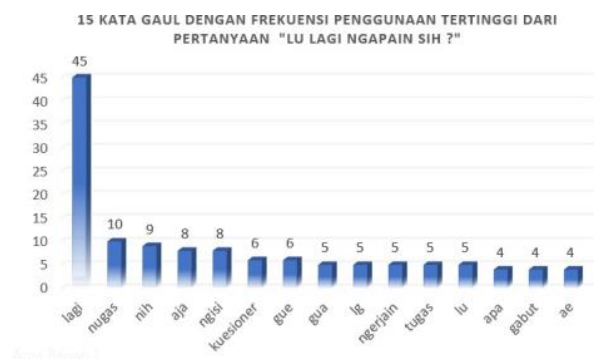

Gambar 7. 15 Kata Gaul Frekuensi Tertinggi Dari Pertanyaan 2

Meskipun data yang didapat menyatakan jumlah responden yang lebih 
memilih menggunakan kata gaul dibanding kata-kata baku sangat banyak, responden, khususnya mahasiswa tetap dapat mengetahui situasi dan kondisi agar tetap menggunakan bahasa Indonesia yang baik dan benar (S et al., 2021). Hal ini dibuktikan dengan grafik responden dalam menggunakan bahasa Indonesia saat berkomunikasi dengan dosen. Dari survei yang telah diberikan, ditinjau empat aspek penggunaan bahasa Indonesia di kalangan mahasiswa yaitu teman sedaerah, teman kampus, dosen, dan luar kampus.

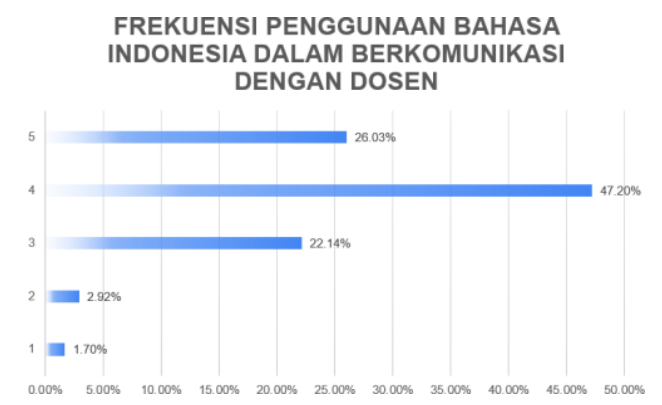

Gambar 8. Frekuensi Penggunaan Bahasa Indonesia Dalam Berkomunikasi Dengan Dosen

Berdasarkan hasil survei penggunaan bahasa Indonesia pada dosen didapatkan bahwa $26.03 \%$ sangat sering, $47.20 \%$ sering, $22.14 \%$ sedang, $2.92 \%$ jarang, dan $1.70 \%$ sangat jarang. dilihat dari hasil survei penggunaan bahasa indonesia dalam berkomunikasi dengan dosen didapatkan bahwa bahasa indonesia masih digunakan oleh mahasiswa dalam berkomunikasi dengan dosen di kampusnya. Dengan begitu, sangat memungkinkan juga bahwa $1.70 \%$ dari total responden yang jarang menggunakan bahasa Indonesia dalam berkomunikasi dengan dosen merupakan kerabat atau sudah berkenalan dekat dengan dosen terkait, atau berasal dari daerah yang sama dengan dosen.

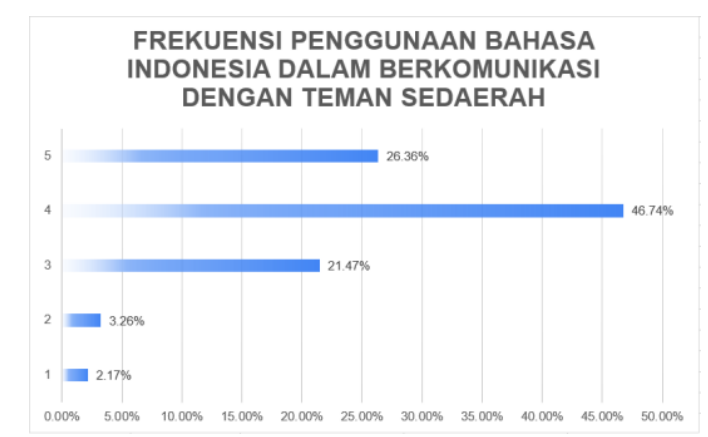

Gambar 9. Frekuensi Penggunaan Bahasa Indonesia Dalam Berkomunikasi Dengan Teman Sedaerah

Dari hasil survei pada teman sedaerah didapatkan bahwa $26.36 \%$ sangat sering, $46.74 \%$ sering, $21.47 \%$ sedang, 3.26\% jarang, dan $2.17 \%$ sangat jarang. dilihat dari hasil survei penggunaan bahasa indonesia dalam berkomunikasi dengan teman sedaerah didapatkan bahwa bahasa indonesia masih digunakan oleh mahasiswa dalam berkomunikasi dengan teman di daerahnya.

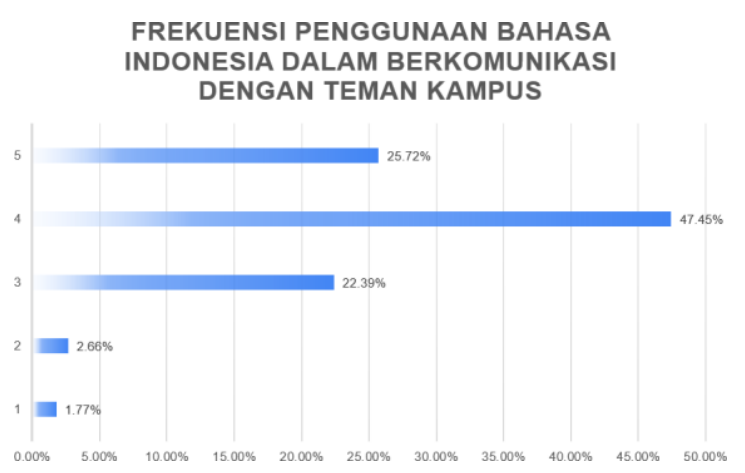

Gambar 10. Frekuensi Penggunaan Bahasa Indonesia Dalam Berkomunikasi Dengan Teman Kampus

Dari hasil survei mengenai
penggunaan bahasa Indonesia dalam
berkomunikasi dengan teman kampus,
didapatkan data bahwa $25.72 \%$ sangat
sering, 47.45\% sering, $22.39 \%$ sedang,
$2.66 \%$ jarang, dan $1.77 \%$ sangat jarang.
Dari hasil tersebut, dapat terlihat dari hasil
survei penggunaan bahasa indonesia
dalam berkomunikasi dengan teman
kampus bahwa bahasa indonesia masih


digunakan oleh mahasiswa dalam berkomunikasi dengan teman di kampusnya.

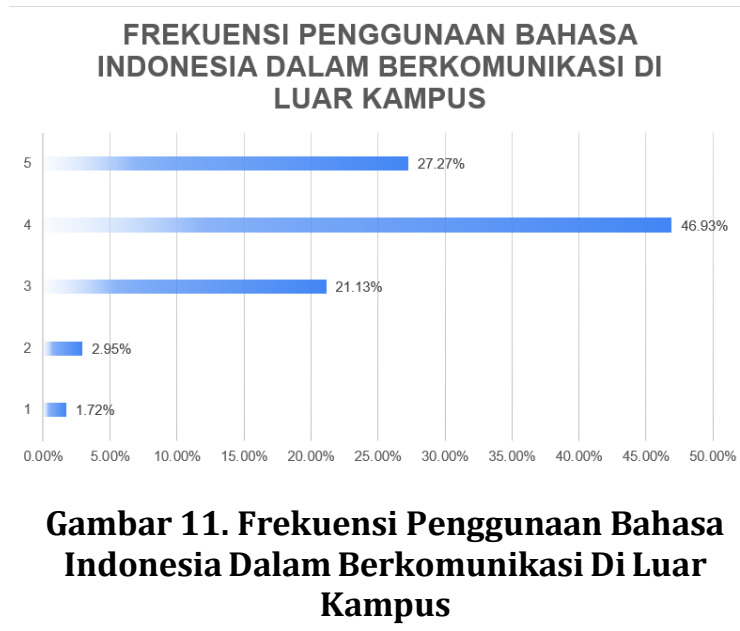

Dari hasil survei pada luar kampus didapatkan bahwa $27.27 \%$ sangat sering, $46.93 \%$ sering, $21.73 \%$ sedang, $2.95 \%$ jarang, dan $1.75 \%$ sangat jarang. dilihat dari hasil survei penggunaan bahasa indonesia dalam berkomunikasi di luar kampus didapatkan bahwa bahasa indonesia masih digunakan oleh mahasiswa dalam berkomunikasi di luar kampus. dari empat aspek tersebut didapatkan penggunaan bahasa indonesia masih sering digunakan oleh mahasiswa. Dilihat dari keempat aspek di atas rataratanya masih relatif rendah dibandingkan dengan penggunaan bahasa gaul di kalangan mahasiswa. Dengan kata lain, penggunaan bahasa gaul sangat mempengaruhi penggunaan bahasa indonesia dikalangan mahasiswa dalam berkomunikasi di kehidupan sehari-hari.

\section{Perkembangan dan kosakata Bahasa Gaul di Kalangan Mahasiswa}

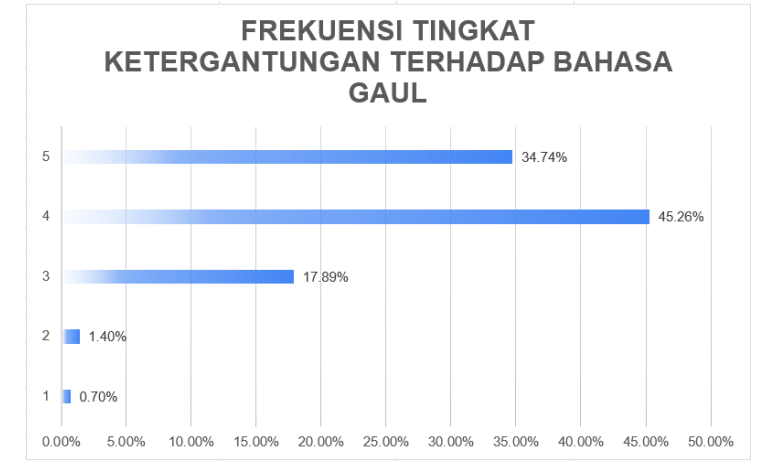

Gambar 12. Frekuensi Tingkat Ketergantungan Terhadap Bahasa Gaul

Berdasarkan diagram di atas, dapat dilihat bahwa ketergantungan mahasiswa terhadap bahasa gaul masih sangat besar dimana $34.74 \%$ sangat ketergantungan dan $45.26 \%$ ketergantungan terhadap bahasa gaul. Dilihat dari diagram diatas ketergantungan penggunaan bahasa gaul di kalangan mahasiswa, dengan kata lain mahasiswa di zaman sekarang sangat tergantung oleh penggunaan bahasa gaul. Dari survei yang dilakukan, diberikan pertanyaan yang mengharuskan responden menjawab sesuai bahasa yang mereka gunakan ketika berkomunikasi di kehidupan sehari-hari.

Dari hasil survei pada gambar 6 dan 7, didapatkan kata-kata gaul yang sering digunakan mahasiswa ketika berkomunikasi sehari-hari. Di zaman sekarang, bahasa gaul berkembang dengan sangat pesat, dibuktikan dengan banyaknya kosakata bahasa indonesia yang diubah sedikit, disingkat, atau di balik antara dua suku katanya agar membentuk kosakata bahasa gaul seperti tabel dibawah ini. 
Tabel 1. contoh kosakata bahasa gaul dan artinya

\begin{tabular}{|c|c|c|}
\hline $\begin{array}{c}\text { Kosakata } \\
\text { Bahasa Gaul }\end{array}$ & Arti & Keterangan \\
\hline Sabi & Bisa & $\begin{array}{c}\text { Terjadi pertukaran } \\
\text { urutan suku kata dari } \\
\text { kosakata Bahasa } \\
\text { Indonesia nya }\end{array}$ \\
\hline Nugas & $\begin{array}{l}\text { Mengerjakan } \\
\text { tugas }\end{array}$ & $\begin{array}{c}\text { Terjadi singkatan } \\
\text { dengan arti Bahasa } \\
\text { Indonesia }\end{array}$ \\
\hline Malem & Malam & $\begin{array}{l}\text { Terjadi perubahan } \\
\text { satu huruf pada } \\
\text { kosakatanya dimana } \\
\text { a diganti e }\end{array}$ \\
\hline Mager & Malas gerak & $\begin{array}{l}\text { Terjadi singkatandari } \\
\text { arti Bahasa } \\
\text { indonesianya }\end{array}$ \\
\hline Gabut & $\begin{array}{l}\text { Sedang tidak } \\
\text { melakukan } \\
\text { pekerjaan/ } \\
\text { kegiatan apa- } \\
\text { apa. } \\
\text { Gaji Buta }\end{array}$ & $\begin{array}{l}\text { Terjadi singkatan } \\
\text { dari arti Bahasa } \\
\text { indonesianya dan } \\
\text { terdapat perubahan } \\
\text { maknayaitu sedang } \\
\text { tidakmelakukan } \\
\text { pekerjaan apa-apa }\end{array}$ \\
\hline Lo-gua-gw & $\begin{array}{l}\text { Merupakan } \\
\text { kata ganti } \\
\text { orang sama } \\
\text { seperti kamu- } \\
\text { saya }\end{array}$ & $\begin{array}{c}\text { Terjadinya } \\
\text { perubahan struktur } \\
\text { kata tetapi memiliki } \\
\text { arti yang sama pada } \\
\text { kosakata Bahasa } \\
\text { indonesia }\end{array}$ \\
\hline
\end{tabular}

\section{Dampak dari Penggunaan Bahasa Gaul}

\section{Dampak Positif}

Dampak positif dari adanya penggunaan bahasa gaul di kalangan mahasiswa adalah remaja menjadi lebih kreatif dalam menggunakan bahasa yang lebih mudah diingat dan mudah diucapkan. Terlepas dari mengganggu atau tidaknya bahasa gaul ini, tidak ada salahnya kita menikmati tiap perubahan atau inovasi bahasa yang muncul asalkan penggunaan bahasa gaul ini pada situasi dan kondisi yang tepat, media yang tepat, pada komunikan yang tepat, serta pada waktu yang tepat (Nurgiansah \& Sukmawati, 2020).

2. Dampak Negatif

Dampak negatif yang dapat diperoleh dari maraknya penggunaan bahasa gaul ini adalah dapat melunturkan penggunaan bahasa Indonesia dalam kehidupan sehari-hari. Bahasa gaul yang ada dapat mempersulit bahasa Indonesia yang baik dan benar. Padahal, penggunaan bahasa Indonesia yang baik dan benar diharuskan dalam lingkungan kampus dan lingkungan masyarakat sebagai representatif mahasiswa.

Bahasa gaul dapat mengganggu siapapun yang membaca dan mendengar kata-kata yang terdapat di dalamnya, karena banyak orang yang tidak memiliki pengertian yang sama akan bahasa gaul tersebut. Terlebih lagi dalam bentuk tulisan, menimbulkan banyak interpretasi dan waktu yang lebih dalam memahaminya. Penggunaan bahasa gaul dapat mempersulit dalam berkomunikasi saat dalam acara formal yang mengharuskan menggunakan bahasa Indonesia yang baik dan benar (Nurgiansah \& Al Muchtar, 2018).

\section{Pengaruh Penggunaan Bahasa Gaul di Kalangan Mahasiswa}

Pada zaman sekarang ini, generasi Z, khususnya kalangan mahasiswa tidak terlepas dari pemakaian bahasa gaul ini, bahkan lebih banyak menggunakan bahasa gaul daripada pemakaian bahasa Indonesia. Untuk menghindari pemakaian bahasa gaul yang tidak pada tempatnya, seharusnya kita dapat menanamkan kecintaan pada diri sendiri terhadap bahasa Indonesia sebagai bahasa nasional. Seiring dengan munculnya bahasa gaul dalam masyarakat, penggunaan bahasa Indonesia sebagai bahasa persatuan tetap diteguhkan dan tidak terdegradasi dengan adanya bahasa gaul ini .

Eksistensi bahasa Indonesia 
terancam terpinggirkan karena adanya bahasa gaul yang mendominasi dalam komunikasi sehari-hari. Dalam kondisi demikian, diperlukan pembinaan dan pemupukan sejak dini kepada generasi $\mathrm{Z}$, khususnya kalangan mahasiswa sebagai agen perubahan agar meminimalisasi pengaruh penggunaan bahasa gaul dalam situasi kondisi tertentu. Adanya pengaruh arus globalisasi cukup mendorong dengan pesat akulturasi budaya bahasa gaul ini.

Hal ini mengakibatkan turunnya derajat bahasa Indonesia dikarenakan penggunaan bahasa gaul yang mudah dalam berkomunikasi dan hanya orang tertentu yang mengerti arti dari bahasa gaul. Sehingga bahasa Indonesia semakin dianggap kuno di mata remaja. Adanya bahasa gaul merupakan pertanda yang harus segera ditangani, bahwa semakin buruknya kemampuan berbahasa generasi muda zaman sekarang yang memungkinkan hilangnya bahasa Indonesia yang disebabkan tergeser oleh bahasa gaul di masa yang akan datang.

Sebagai mahasiswa yang memiliki potensi, posisi, dan peran seharusnya bisa mencegah hal ini terjadi dengan terus melestarikan budaya bahasa Indonesia dengan menggunakan bahasa Indonesia yang baik dan benar dalam kehidupan sehari-hari, dan meminimalisasi penggunaan bahasa gaul terlebih digunakan hanya dalam situasi kondisi serta komunikan tertentu.

\section{KESIMPULAN}

Berdasarkan penelitian yang telah dilakukan, mengenai "Analisis Pengaruh Bahasa Gaul di Kalangan Mahasiswa Terhadap Bahasa Indonesia di Zaman Sekarang" dapat ditarik kesimpulan bahwa banyaknya mahasiswa yang menggunakan bahasa gaul, singkatan-singkatan dalam komunikasinya sehari-hari yang merupakan suatu bentuk kekeliruan dalam penggunaan bahasa Indonesia dengan baik dan benar. Hal ini dapat menghambat pertumbuhan dan perkembangan Bahasa Indonesia yang nantinya akan berdampak pada hilangnya bahasa Indonesia yang tergeser akibat bahasa gaul di masa yang akan datang. Hal ini dapat dicegah dengan meningkatkan kembali kesadaran mencintai bahasa Indonesia terutama pada kalangan generasi $\mathrm{Z}$ yang akan meneruskan kepemimpinan di masa depan.

Sebagai mahasiswa yang memiliki posisi, potensi, dan peran dapat menyebarkan penggunaan bahasa Indonesia dalam kehidupan sehari-hari agar dapat dijadikan budaya dan kebiasaan sehingga penggunaan Bahasa Indonesia akan terus terlestarikan. Penyebaran aksi bangga dengan bahasa Indonesia juga dapat dilakukan dalam berbagai platform media sosial sebagai bentuk penerapan dalam berkomunikasi dimanapun dan kapanpun. Diharapkan hal ini dapat mengurangi dampak negatif dari penggunaan bahasa gaul dalam kehidupan sehari-hari dan kembali meningkatkan bahasa Indonesia yang baik dan benar.

\section{DAFTAR PUSTAKA}

Dewantara, J. A., Hermawan, Y., Yunus, D., Prasetiyo, W. H., Efriani, Arifiyanti, F., \& Nurgiansah, T. H. (2021). Anti-Corruption Education as an Effort to Form Students With Character Humanist and Law-Compliant. Jurnal Civics: Media Kajian Kewarganegaraan, 18(1), 7081.

Dewantara, J. A., \& Nurgiansah, T. H. (2021a). Building Tolerance Attitudes Of PPKN Students Through Multicultural Education Courses. Jurnal Etika Demokrasi, 6(1), 103-115.

Dewantara, J. A., \& Nurgiansah, T. H. (2021b). Peningkatan Keaktifan Belajar Melalui Penerapan Model Picture And Picture Dalam Pembelajaran PPKn di Sekolah Dasar. Jurnal Publikasi Pendidikan, 11(3), 234-241. 
Dewantara, J. A., \& Nurgiansah, T. H. (2021c). Strengthening Pancasila Values During the Covid-19 Pandemic. Edukatif: Jurnal Ilmu Pendidikan, 3(4), 2411-2417.

Dewantara, J. A., Nurgiansah, T. H., \& Rachman, F. (2021). Mengatasi Pelanggaran Hak Asasi Manusia dengan Model Sekolah Ramah HAM (SR-HAM). Edukatif: Jurnal Ilmu Pendidikan, $3(2), 261-269$.

Keraf, G. D. (2009). Diksi dan gaya bahasa. Gramedia Pustaka Utama.

Mulyana, (2008). Bahasa Indonesia untuk Perguruan Tinggi. Rembang : Yayasan Adhigama

Nurgiansah, T. H. (2020). Pelatihan Penulisan Artikel Ilmiah Bagi Mahasiswa PPKn Universitas PGRI Yogyakarta. JNPM: Jurnal Nasional Pengabdian Masyarakat, 1(1), 16-23.

Nurgiansah, T. H. (2021a). Partisipasi Politik Masyarakat Sleman di Masa Pandemi Covid-19 dalam Konteks Pendidikan Kewarganegaraan. Jurnal Civic Hukum, 6(1), 1-9.

Nurgiansah, T. H. (2021b). Pemanfaatan E-Learning Dalam Pembelajaran Pendidikan Kewarganegaraan. JINTECH: Journal of Information Technology, 2(2), 138-146.

Nurgiansah, T. H., \& Al Muchtar, S. (2018). Development of Student Awareness through Student Learning Model Jurisprudential in Citizenship Education. ATLANTIS PRESS, 251(Acec), 670-674. https://doi.org/10.2991/acec-18.2018.150

Nurgiansah, T. H., \& Sukmawati. (2020). Tantangan Guru Pendidikan Kewarganegaraan Di Masa Adaptasi Kebiasaan Baru. Jurpis: Jurnal Pendidikan Ilmu Sosial, 17(2), 139-149.

Rachman, F., Nurgiansah, T. H., \& Kabatiah, M. (2021). Profilisasi Pendidikan Kewarganegaraan dalam Kurikulum Pendidikan Indonesia. Edukatif: Jurnal Ilmu Pendidikan, 3(5), 2970-2984.

Rachman, F., Ryan, T., Kabatiah, M., Batubara, A., Pratama, F. F., \& Nurgiansah, T. H. (2021). Pelaksanaan Kurikulum PPKn pada Kondisi Khusus Pandemi Covid-19. Jurnal Basicedu, 5(6), 5682-5691.

Rastati, R. (2018). Media Literasi Bagi Digital Natives: Perspektif Generasi Z di Jakarta. Kwangsan, 6(1), 286903.

S, H. C., Alamsyah, M., Izzrufi, M. I., L, S. R., \& Saepudin, E. (2021). Persepsi Mahasiswa/i Terhadap Wacana Amandemen UUD NRI 1945 (Survei terhadap Mahasiswa STEI ITB Angkatan 2018). Jurnal Kewarganegaraan, 5(1), 13-20.

Sarwono, 2004."Penggunaan Ragam Bahasa Gaul Dikalangan Remaja". Dalam http://www.penggunaan-ragam-bahas a-gauldikalanganremaja. Diakses pada Senin, 22 November 2021 pukul 21.00 WIB. 